\title{
Deteç̧ão de Escherichia coli 0157:H7 inoculada experimentalmente em amostras de leite cru por método convencional e PCR multiplex
}

\author{
[Detection of E. coli O157:H7 experimentally inoculated in raw milk samples \\ by conventional method and multiplex $P C R]$ \\ P.M. Garcia ${ }^{1}$, E.F. Arcuri ${ }^{2 *}$, M.A.V.P. Brito ${ }^{2}$, C.C. Lange $^{2}$, J.R.F. Brito ${ }^{2}$, M.M.O.P. Cerqueira ${ }^{3}$ \\ ${ }^{1}$ Aluno de pós-graduação - EV-UFMG - Belo Horizonte, MG \\ ${ }^{2}$ Embrapa Gado de Leite \\ Rua Eugênio do Nascimento, 610 \\ 36038-330 - Juiz de Fora, MG \\ ${ }^{3}$ Escola de Veterinária - UFMG - Belo Horizonte, MG
}

\begin{abstract}
RESUMO
Padronizou-se um método de reação em cadeia da polimerase (PCR) multiplex para detecção de Escherichia coli O157:H7 e avaliou-se a eficiência da PCR e de um método de cultivo convencional em placas na deteç̧ão desse patógeno experimentalmente adicionado em leite estéril e em leite cru com baixa contagem bacteriana total (média de 4,01 x $10^{3} \mathrm{UFC} / \mathrm{ml}$ ) e com alta contagem bacteriana (média de 2,10 x $10^{6} \mathrm{UFC} / \mathrm{ml}$ ). Foram padronizadas duas reações de PCR com o uso dos primers: "A" (RfbF; RfbR e FLICh7F/FLICh7R) e "B" (SLT-IF/SLTIR e SLT-IIF/SLT-IIR). A detecção de E. coli O157:H7 (1UFC/ml) a partir do leite estéril e do leite cru com baixa contaminação bacteriana foi possível quando se utilizou o método de contagem em placas e a PCR. A sensibilidade dos dois métodos foi menor quando se testou o leite cru com alta contaminação microbiana, sendo o método convencional mais sensível. Os resultados indicam que a presença de outros microrganismos, em alta quantidade no leite, dificulta a detecção de E. coli O157:H7 pelos métodos utilizados.
\end{abstract}

Palavras-chave: PCR multiplex, E. coli $\mathrm{O} 157: \mathrm{H} 7$, antígeno O157, antígeno H7, genes para toxina tiposhiga

\begin{abstract}
This experiment was carried out in order to evaluate the effect of the raw milk bacterial count on the efficiency of a multiplex polymerase chain reaction and a conventional plate count method for detection of Escherichia coli O157:H7. This pathogen was experimentally inoculated into sterile milk, raw milk with low bacterial count (count mean of $4.01 \times 10^{3} \mathrm{cfu} / \mathrm{ml}$ ) and, raw milk with high bacterial count (mean $2.10 \times 10^{6} \mathrm{cfu} / \mathrm{ml}$ ). Two protocols of PCR were standardized using primers "A" (Rfbf and Rfbr and FLICh7F/FLICh7R) and "B" (SLT-IF/SLTIR and SLT-IIF/SLT-IIR). Both conventional plate count and PCR methods were able to detect the presence of E. coli O157:H7 in either sterile milk or raw milk with low bacterial count initially inoculated with 1cfu of E. coli O157:H7 per ml. The sensibility of both methods for high-contaminated raw milk samples was lower, being the conventional approach more sensitive. These results indicate that high bacterial count in raw milk can affect E. coli O157:H7 detection.
\end{abstract}

Keywords: PCR multiplex, E. coli O157:H7, O157 antigen, $H 7$ antigen, shiga-like toxin genes

Recebido em 10 de julho de 2007

Aceito em 3 de junho de 2008

E-mail: edna@cnpgl.embrapa.br 


\section{INTRODUÇÃO}

Escherichia coli $\mathrm{O} 157: \mathrm{H} 7$ é um sorotipo de $E$. coli pertencente ao grupo EHEC (E. coli enterohemorrágicas). Esse grupo inclui estirpes que produzem fatores citotóxicos descritos como verotoxinas (VTs) ou Shiga-like toxinas (SLTs) (Doyle et al., 1997). Emergente nas últimas décadas, esse microrganismo é um importante patógeno causador de doença de transmissão alimentar (DTA) e, apesar de sua incidência relativamente baixa, constitui sério risco à saúde, sendo, algumas vezes, fatal, particularmente para crianças e para idosos (Foodborne..., 2002).

Desde sua identificação em 1982, E. coli O157:H7 tem sido isolada em numerosos surtos envolvendo colite hemorrágica e síndrome hemolítica urêmica (Kuntz e Kuntz, 1999). Como agente de DTA, tem sido especialmente associada ao consumo de alimentos de origem animal como carnes, leites e produtos derivados (Mechie et al., 1997), uma vez que rebanhos bovinos leiteiros e de corte são os principais reservatórios para infecção humana por E. coli O157 (Griffin e Tauxe, 1991).

A técnica de reação em cadeia da polimerase (PCR) é um grande avanço no diagnóstico molecular de microrganismos patogênicos. PCR multiplex, técnica que detecta simultaneamente duas ou mais seqüências de DNA, tem sido utilizada na deteç̧ão de $E$. coli (Hu et al., 1999; Bottero et al., 2004; Macedo et al., 2007) e constitui uma alternativa importante na deteç̧ão desse patógeno em leite e derivados.

Cerqueira et al. (1999) relataram alta incidência de STEC (Shiga-toxin producing E. coli) em bovinos sadios no estado do Rio de Janeiro (71\% de portadores). Em gado leiteiro, a freqüência de isolamento foi de $82 \%$ e em gado de corte, $53 \%$. Desses isolados, três $(1,5 \%)$ foram identificados como E. coli O157:H7, sendo esse provavelmente o primeiro trabalho a relatar o isolamento desse sorotipo no Brasil. Ainda não se tem nenhum relato da ocorrência de $E$. coli O157:H7 em leite e derivados no Brasil, talvez pela dificuldade de detecção quando esse microrganismo está presente em número pequeno devido, por exemplo, à interferência da microbiota endógena do leite.
Este trabalho teve como objetivos padronizar um método de PCR multiplex para detecção de $E$. coli $\mathrm{O} 157: \mathrm{H} 7$ e avaliar a eficiência dessa técnica, e de um método de cultivo convencional em placas, na detecção desse patógeno, inoculado experimentalmente em leite cru com baixa e alta contaminação microbiana.

\section{MATERIAL E MÉTODOS}

O trabalho foi desenvolvido nos Laboratórios de Microbiologia do Leite e de Genética Molecular da Embrapa Gado de Leite em Juiz de Fora, Minas Gerais.

Para avaliar a sensibilidade e a especificidade do método de PCR multiplex foram utilizadas 30 estirpes de Escherichia coli e 14 pertencentes a outros gêneros bacterianos: Listeria monocytogenes (2), Listeria innocua, Listeria welshimeri, Pseudomonas aeruginosa, Staphylococcus aureus, Enterobacter cloaceae, Enterobacter sakazakii (2), Salmonella Typhi, Salmonella Typhimurium, Salmonella Dublin, Klebsiella pneumoniae e Shigella sonnei. Dentre as estirpes de E. coli, cinco eram E. coli O157:H7, uma $E$. coli O157 (IAL 0411), uma $E$. coli ATCC 11775, uma E. coli ATCC 25922, cinco $E$. coli (EPEC) e 17 E. coli isoladas de leite de vacas com mastite. Todas as estirpes de $E$. coli tiveram sua identificação confirmada por meio do Sistema API 20E $E^{1}$.

Na extração de DNA microbiano utilizaram-se três métodos. Para cultura em meio líquido (caldo de enriquecimento), o DNA foi extraído pelo método fenol-clorofórmio (Jersek et al., 1996) e pelo método de lise térmica (Nunes et al., 1999). Para cultura em meio sólido, utilizouse o método de lise térmica diretamente da colônia (Hu et al., 1999). O DNA foi quantificado em espectrofotômetro ${ }^{2}$ e $\quad$ a concentração foi ajustada para $20 \mathrm{ng} / \mu \mathrm{l}$.

Os primers testados para E. coli $\mathrm{O} 157: \mathrm{H} 7$ na reação de PCR foram propostos por Hu et al. (1999): RfbF 5'GTGTCCATTTATACGGACATCCATG-3' e RfbR CCTATAACGTCATGCCAATATTGCC-3'

\footnotetext{
${ }^{1}$ BioMérieux SA-Marcy-l'Etoile, França.

${ }^{2}$ GeneQuantpro, Healthcare GE Life Science- Upsala, Suécia.
} 
para o gene $r f b E$, gerando um produto amplificado de 292 pb; FLICh7-F 5'GCGCTGTCGAGTCTATCGAGC-3' e FLICh7-R 5'CAACGGTGACTTATCGCCATTCC-3' para o gene fliC (625 pb); SLT-1F 5'TGTAACTGGAAAGGTGGAGTATAC-3' e SLT-1R 5'GCTATTCTGAGTCAACGAAAAATAAC-3' para o gene slt $(210 \mathrm{pb})$; SLT-IIF 5'GTTTTTCTTCGGTATCCTATTCCG-3' e SLT-IIR 5'-GATGCATCTCTGGTCATTG

TATTA C-3' para o gene $s_{2} t_{2}(484 \mathrm{pb})$. Os genes $r f b E$ e $f l i C$ estão envolvidos na biossíntese dos antígenos somático $\mathrm{O} 157$ e flagelar H7, respectivamente, os genes slt $_{1}$ e slt $_{2}$ codificam toxinas semelhantes àquelas produzidas por Shigella dysenteriae e estão presentes no grupo de E. coli denominado STEC (Shiga-toxin E. coli).

A PCR foi realizada por dois diferentes protocolos: (i) em uma única reação, nas condições descritas por $\mathrm{Hu}$ et al. (1999), avaliando os quatro pares de primers $\mathrm{RfbF} / \mathrm{RfbR}$, FLIC $_{\mathrm{h} 7}$ F/FLIC ${ }_{\mathrm{h} 7} \mathrm{R}$, SLT-IF/SLTIR e SLTIIF/SLT-IIR, utilizando estirpes de $E$. coli O157:H7, e (ii) em duas reações, "A" (com $\mathrm{RfbF} / \mathrm{RfbR}$ e FLIC $_{\mathrm{h} 7} \mathrm{~F} / \mathrm{FLIC}_{\mathrm{h} 7} \mathrm{R}$ ) e "B" (com SLT-IF/SLTIR e SLT-IIF/SLT-IIR). A reação "A" com $5 \mu$ l de tampão de PCR (10X), $1 \mu l$ da mistura de dNTPs (10mM); $1 \mathrm{U}$ de taq DNA polimerase; 2,5mmol/1 de $\mathrm{MgCl}_{2} ; 20$ pmol de cada oligonucleotídeo $\mathrm{FLIC}_{\mathrm{h} 7}, 30 \mathrm{pmol}$ de cada $\mathrm{Rfb}, 2,5 \mu \mathrm{l}$ de DNA bacteriano (20ng/ $\mu \mathrm{l})$ e água bidestilada para completar o volume total de $50 \mu 1$. A reação " $\mathrm{B}$ " foi idêntica à reação " $\mathrm{A}$ ", mas com 50pmol de cada oligonucleotídeo. As misturas " $\mathrm{A}$ " $\mathrm{e}$ " $\mathrm{B}$ " foram aquecidas por cinco minutos a $94^{\circ} \mathrm{C}$, submetidas a 35 ciclos de amplificação (desnaturação a $94^{\circ} \mathrm{C}$ por $30 \mathrm{~s}$, anelamento a $57^{\circ} \mathrm{C}$ por um minuto e extensão a $72^{\circ} \mathrm{C}$ por um minuto) e extensão final a $72^{\circ} \mathrm{C} / 10 \mathrm{~min}$ em termociclador ${ }^{3}$.

Os fragmentos de DNA amplificados foram separados por eletroforese em gel de agarose a $1,6 \%$, corados com solução de brometo de etídio $(0,005 \%, \quad \mathrm{p} / \mathrm{v})$ e fotografados em fotodocumentador ${ }^{4}$.

${ }^{3}$ GeneAmp PCR System 960, Applied Biosystems - Foster City, CA, EUA.

${ }^{4}$ Eagle Eye II, Stratagene - La Jolla, EUA.
Inicialmente um cultivo de $E$. coli $\mathrm{O} 157: \mathrm{H} 7$ (IAL 1848) foi diluído até a extinção celular (fator de diluição de $10^{12}$ ) para determinar as diluições que continham $1000,100,10,1$ e $0 \mathrm{UFC} / \mathrm{ml}$ por meio de contagem em Petrifilm ${ }^{\mathrm{TM}}$. Essas mesmas diluições foram utilizadas na avaliação da sensibilidade da PCR para detectar E. coli O157:H7 inoculada experimentalmente em leite esterilizado e leite cru com diferentes contagens de microrganismos contaminantes (baixa e alta contaminação definidas pela contagem bacteriana total - CBT) após enriquecimento em caldo EC.

Diluições decimais de uma cultura de E. coli O157:H7 crescida em caldo BHI por $24 \mathrm{~h} / 35^{\circ} \mathrm{C}$ foram feitas, diluindo-se $0,6 \mathrm{ml}$ da cultura em $5,4 \mathrm{ml}$ de tampão fosfato, até se obter a extinção celular (Fig. 1). Para as diluições com cerca de $100,10,1$ e $0 \mathrm{UFC} / \mathrm{ml}$ foi feito plaqueamento em duplicata de $1 \mathrm{ml} /$ placas de Petrifilm (para determinar UFC/ml após 24 horas de incubação a $35^{\circ} \mathrm{C}$ ) e inoculação de $1 \mathrm{ml}$ em cada três frascos contendo $24 \mathrm{ml}$ de leite em pó reconstituído estéril $^{5}$ ou leite cru. Cada um desses volumes de $25 \mathrm{ml}$ foi acrescentado em $225 \mathrm{ml}$ de caldo $\mathrm{EC}^{6}$ com novobiocina, $(100 \mathrm{mg} / \mathrm{ml})^{7}$. Incubaram-se os frascos por $24 \mathrm{~h} / 35^{\circ} \mathrm{C}$ e foi realizada a extração de DNA de $1 \mathrm{ml}$ da cultura de cada frasco pelo método de lise térmica (Nunes et al., 1999) e pelo método de fenol-clorofórmio (Jersek et al., 1996). O DNA obtido foi usado na PCR multiplex (reação "A") para determinar o menor número de bactérias presentes no leite que o método é capaz de detectar. Também foi feito o plaqueamento segundo o método convencional. Para cada tipo de leite o ensaio foi repetido duas vezes visando a analisar a repetibilidade dos métodos de detecção.

O leite cru com baixa contaminação (CBT inferior a $1 \times 10^{4} \mathrm{UFC} / \mathrm{ml}$ ) utilizado foi obtido na Embrapa Gado de Leite, Coronel Pacheco, MG, e o de alta contaminação microbiana (CBT maior que 1 x $10^{6} \mathrm{UFC} / \mathrm{ml}$ ), no Instituto de Laticínios Cândido Tostes/EPAMIG, Juiz de Fora, MG.

\footnotetext{
${ }^{5}$ Molico desnatado, Nestlé - Araçatuba, Brasil

${ }^{6}$ Difco - Sparks, MD, EUA.

${ }^{7}$ Sigma - St. Louis, MO, EUA.
} 


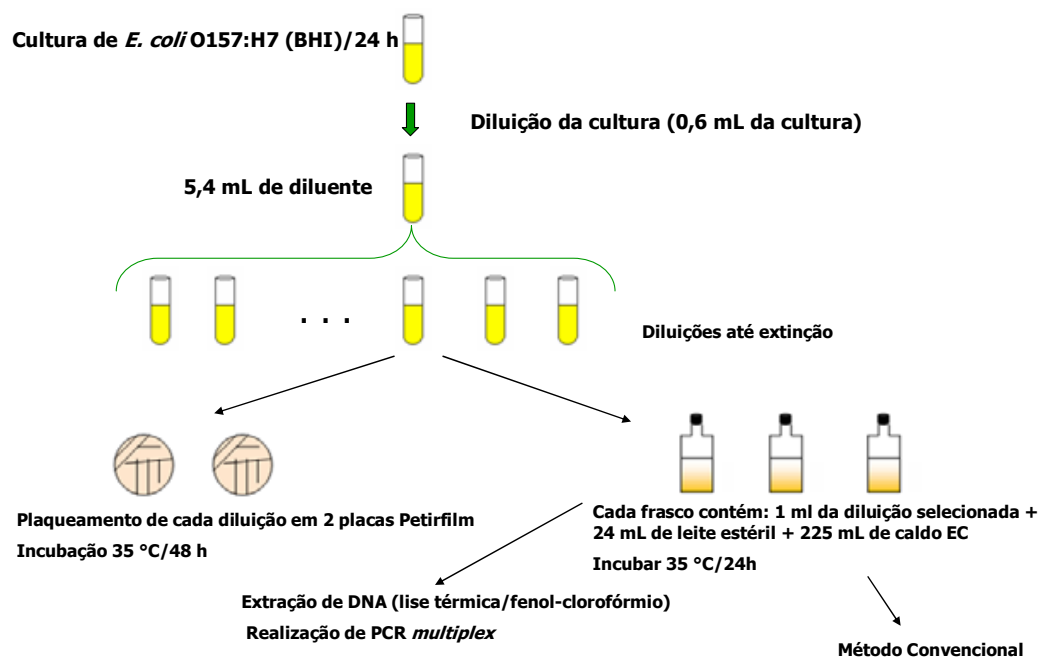

Figura 1. Fluxograma para determinação da sensibilidade da técnica de PCR em detectar E. coli O157:H7 em leite esterilizado $\left(110^{\circ} \mathrm{C} / 10 \mathrm{~min}\right)$, comparando-o com o método convencional em placas.

As mesmas amostras de leite estéril e leite cru (com baixa CBT e com alta CBT) foram inoculadas com $E$. coli $\mathrm{O} 157: \mathrm{H} 7$ e, após enriquecimento em caldo $\mathrm{EC}$ a $35^{\circ} \mathrm{C} / 24 \mathrm{~h}$, foram plaqueadas com alça de $50 \mu \mathrm{l}$ em 12 placas de meio TC-SMAC (com 0,05mg/l de CefiximeDynal e $2,5 \mathrm{mg} / 1$ de telurito de potássio ${ }^{8}$ ) por inóculo testado e incubadas a $35^{\circ} \mathrm{C} / 24 \mathrm{~h}$. Uma colônia de cada placa, com morfologia típica de E. coli $\mathrm{O} 157: \mathrm{H7}$ e sorbitol negativa, foi transferida para o meio EC-MUG e incubada novamente por mais $24 \mathrm{~h}$ a $35^{\circ} \mathrm{C}$. Após esse período de incubação, as colônias que não fluoresceram na presença de luz ultravioleta, denominadas colônias MUG negativas, foram testadas com soro anti O157, seguindo as recomendações do fabricante. Aquelas positivas neste teste foram inoculadas em meio de motilidade SIM para posterior teste com soro anti $\mathrm{H}^{9}$ seguindo as recomendações do fabricante. A extração de DNA foi realizada diretamente da colônia em meio EC-MUG (Hu et al., 1999) que foi positiva no teste do soro anti O157.

\section{RESULTADOS E DISCUSSÃO}

Neste experimento, quando se tentou reproduzir a reação de PCR com os quatro pares de primers para os genes $r f b E$, fliC, $s l t_{1}$ e $s l t_{2}$, como proposta por $\mathrm{Hu}$ et al. (1999), não foi verificada a amplificação simultânea dos quatro produtos esperados, mesmo após diversas tentativas de otimização da reação com variação da temperatura de anelamento, das concentrações de $\mathrm{MgCl}_{2}$ e das concentrações dos primers. Entretanto, em misturas separadas, "A" (específica para genes dos antígenos $\mathrm{O} 157$ e H7) e "B" (específica para os genes das toxinas SLTI e SLT-II), nas mesmas condições no termociclador, houve a amplificação dos fragmentos esperados. Os quatro pares de primers apresentam tm (melting temperature) variando entre 68 e $72^{\circ} \mathrm{C}$, o que possibilitou eficiência similar para cada par de primers quando testados sob as mesmas condições de temperatura de anelamento. Além disso, os diferentes tamanhos dos produtos de amplificação em cada reação (mistura "A": $292 \mathrm{pb}$ e $625 \mathrm{pb}$ e mistura "B": $210 \mathrm{pb}$ e $484 \mathrm{pb}$ ) facilitaram sua diferenciação em gel de agarose. Os resultados obtidos (Tab. 1) mostram que a PCR multiplex nas duas reações "A" e "B" estabelecidas são suficientes para o diagnóstico de E. coli O157:H7. Dentre as bactérias analisadas, apenas E. coli O157:H7 apresentou os produtos de amplificação esperados, indicando total especificidade da técnica para detecção de E. coli O157:H7, em concordância com o trabalho de Hu et al. (1999).

${ }^{8}$ Dynal Biotech A.S.A - Oslo, Noruega.

${ }^{9}$ Bacto E. coli $\mathrm{H}$ antiserum H7, Difco - Sparks, EUA. 
Tabela 1. Estirpes bacterianas e resultados da PCR

\begin{tabular}{lccccc}
\multicolumn{1}{c}{ Microorganismo } & Número de & \multicolumn{3}{c}{ PCR - Número de estirpes } \\
pestirpes & testadas & H7 & O157 & SLTI & SLTII \\
\hline E. coli O157:H7 & 5 & 5 & 5 & 1 & 5 \\
E. coli O157 K88ac H11 A2 (IAL 0411) & 1 & 0 & 1 & 0 & 0 \\
E. coli H7 O1 K1 (ATCC 11775) & 1 & 1 & 0 & 0 & 0 \\
E. coli (ATCC 25922) & 1 & 0 & 0 & 0 & 0 \\
E. coli isoladas de mastite & 178 & 2 & 0 & 0 & 0 \\
E. coli enteropatogênica (CNPGL) & 5 & 1 & 0 & 0 & 0 \\
Salmonella Typhimurium (IAL 1472) & 1 & 0 & 0 & 0 & 0 \\
Salmonella Typhi (IAL 1251) & 1 & 0 & 0 & 0 & 0 \\
Salmonella Dublin (CNPGL 5672) & 1 & 0 & 0 & 0 & 0 \\
Enterobacter cloaceae (CDC 3430) & 1 & 0 & 0 & 0 & 0 \\
Enterobacter sakazakii (CDC 7006/7007) & 2 & 0 & 0 & 0 & 0 \\
Pseudomonas aeruginosa (ATCC 27853) & 1 & 0 & 0 & 0 & 0 \\
Klebsiella pneumoniae (ATCC 13883) & 1 & 0 & 0 & 0 & 0 \\
Shigella sonnei CIP 6310 (IAL 1585) & 1 & 0 & 0 & 0 & 0 \\
Listeria monocytogenes (ATCC 19117/SCOTTA) & 2 & 0 & 0 & 0 & 0 \\
Listeria innocua (IAL 1984) & 1 & 0 & 0 & 0 & 0 \\
Listeria welshimeri (IAL 1819) & 1 & 0 & 0 & 0 & 0 \\
Staphylococcus aureus (CNPGL 5344) & 1 & 0 & 0 & 0 & 0 \\
\hline
\end{tabular}

Na Fig. 2 mostra-se a eficiência da PCR quando se utilizaram os dois métodos de extração de DNA: fenol-clorofórmio (Jersek et al., 1996) e de lise térmica (Nunes et al., 1999), para leite estéril inoculado com E. coli $\mathrm{O} 157: \mathrm{H} 7$, antes e após cultivo de enriquecimento em caldo EC. Uma vez que ambos os métodos de extração de DNA permitiram amplificação dos fragmentos específicos após o cultivo em caldo EC, adotouse o método de lise térmica devido à sua simplicidade e rapidez.

A sensibilidade e especificidade do método são particularmente importantes quando se analisam alimentos. Para E. coli O157:H7, a dose infectante pode ser inferior a 10UFC (Armstrong et al., 1996). Embora não existam padrões microbiológicos estabelecidos para $E$. coli O157:H7 na legislação brasileira, a presença de 1 a $10 \mathrm{UFC} / \mathrm{ml}$ pode ser capaz de causar doença no homem e, desse modo, não deve ser permitida a sua presença em nenhuma amostra de alimento (ausência em $25 \mathrm{~g}$ ou $25 \mathrm{ml}$ ).

O método convencional e o método PCR apresentaram alta sensibilidade na detecção do patógeno, pois este foi detectado quando o inóculo de E. coli O157:H7 foi de 1 ou $2 \mathrm{UFC}$, tanto no leite estéril, como no leite com baixo número de microrganismos acompanhantes (Tab. 2 e 3 ).

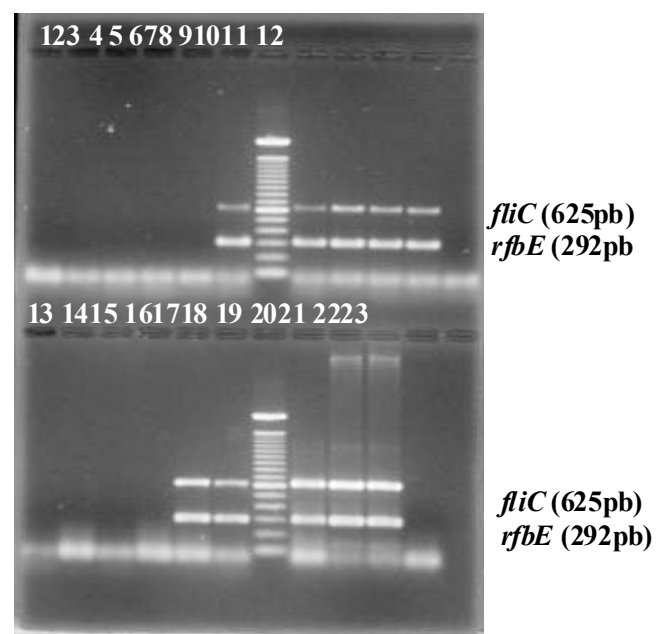

Figura 2. Detecção dos genes $r f b$ e fliC em $E$. coli $0157: \mathrm{H} 7$ inoculada em leite estéril nas concentrações de 2,62 x $10^{4} \mathrm{UFC} / \mathrm{ml}, 2,62 \times$ $10^{3} \mathrm{UFC} / \mathrm{ml}, 2,62 \times 10^{2} \mathrm{UFC} / \mathrm{ml}, 37 \mathrm{UFC} / \mathrm{ml} \mathrm{e}$ $4 \mathrm{UFC} / \mathrm{ml}$, antes e após enriquecimento em caldo $\mathrm{EC}$, testando dois métodos de extração de DNA (lise térmica e fenol-clorofórmio). Método de lise térmica diretamente do leite: 1 a 5; método de lise térmica após enriquecimento: 6 a 11; método fenol-clorofórmio diretamente do leite: 12 a 16; método fenol-clorofórmio após enriquecimento: 17 a 22; 7 e 19: marcador de peso molecular (100pb); 23: controle negativo. 


\section{Garcia et al.}

Tabela 2. Comparação do método convencional e do método PCR na detecção de E. coli O157:H7 inoculada até a extinção em leite estéril

\begin{tabular}{cccccccc}
\hline \multirow{2}{*}{ Leite estéril } & Inóculo de E. coli & \multicolumn{3}{c}{ Convencional } & \multicolumn{3}{c}{ PCR } \\
\cline { 2 - 7 } Teste 1 & O157:H7 (UFC) & $\mathrm{A}^{*}$ & $\mathrm{~B}^{*}$ & $\mathrm{C}^{*}$ & $\mathrm{~A}^{*}$ & $\mathrm{~B}^{*}$ & $\mathrm{C}^{*}$ \\
& 24 & + & + & + & + & + & + \\
& 2 & + & + & - & + & + & - \\
Teste 2 & 0 & - & - & - & - & - & - \\
& 0 & - & - & - & - & - & - \\
& 1 & + & + & + & + & + & + \\
& 0 & + & + & - & + & + & - \\
& 0 & - & - & - & - & - & - \\
\hline
\end{tabular}

* A, B e C: repetição.

+: positivo após incubação a $35^{\circ} \mathrm{C} / 24 \mathrm{~h}$ em meio de enriquecimento (Caldo EC).

-: negativo após incubação a $35^{\circ} \mathrm{C} / 24 \mathrm{~h}$ em meio de enriquecimento (Caldo EC).

Tabela 3. Comparação dos métodos convencional e PCR na detecção de E. coli O157:H7 experimentalmente inoculada até a extinção, em leite cru com baixa contaminação microbiana

\begin{tabular}{|c|c|c|c|c|c|c|c|}
\hline \multirow{2}{*}{$\begin{array}{l}\text { Qualidade microbiológica do leite } \\
\text { cru inoculado }\end{array}$} & \multirow{2}{*}{$\begin{array}{c}\text { Inóculo de } E \text {. coli } \\
\text { O157:H7 } \\
\text { (UFC) }\end{array}$} & \multicolumn{3}{|c|}{ Convencional } & \multicolumn{3}{|c|}{ PCR } \\
\hline & & $\mathrm{A}^{*}$ & $\mathrm{~B}^{*}$ & $\mathrm{C}^{*}$ & $A^{*}$ & $\mathrm{~B}^{*}$ & $\mathrm{C}^{*}$ \\
\hline \multirow[t]{2}{*}{ Teste 1} & Incontável & + & + & + & + & + & + \\
\hline & 170 & + & + & + & + & + & + \\
\hline CBT: $3,55 \times 10^{3} \mathrm{UFC} / \mathrm{ml}$ & 18 & + & + & + & + & + & + \\
\hline \multirow[t]{3}{*}{ Coliformes: $3,90 \times 10^{2} \mathrm{UFC} / \mathrm{ml}$} & 2 & + & + & + & + & + & + \\
\hline & 1 & - & - & - & - & - & - \\
\hline & 0 & - & - & - & - & - & - \\
\hline \multirow[t]{2}{*}{ Teste 2} & Incontável & + & + & + & + & + & + \\
\hline & 237 & + & + & + & + & + & + \\
\hline CBT: $3,90 \times 10^{3} \mathrm{UFC} / \mathrm{ml}$ & 32 & + & + & + & + & + & + \\
\hline \multirow[t]{3}{*}{ Coliformes: $5 \times 10^{1} \mathrm{UFC} / \mathrm{ml}$} & 2 & - & + & + & - & + & + \\
\hline & 1 & - & - & - & - & - & + \\
\hline & 0 & - & - & - & - & - & - \\
\hline \multirow[t]{2}{*}{ Teste 3} & Incontável & + & + & + & + & + & + \\
\hline & 223 & + & + & + & + & + & + \\
\hline CBT: $4,60 \times 10^{3} \mathrm{UFC} / \mathrm{ml}$ & 22 & + & + & + & + & + & + \\
\hline \multirow[t]{3}{*}{ Coliformes: $8 \times 10^{1} \mathrm{UFC} / \mathrm{ml}$} & 3 & + & + & + & + & + & + \\
\hline & 1 & + & + & - & + & + & - \\
\hline & 0 & - & - & - & - & - & - \\
\hline
\end{tabular}

CBT: contagem bacteriana total.

* A, B e C: repetição.

+: positivo após incubação a $35^{\circ} \mathrm{C} / 24 \mathrm{~h}$ em meio de enriquecimento (Caldo EC).

-: negativo após incubação a $35^{\circ} \mathrm{C} / 24 \mathrm{~h}$ em meio de enriquecimento (Caldo EC).

No caso do leite cru com alta contaminação bacteriana, a sensibilidade foi menor para os dois métodos, sendo o método convencional mais sensível que a PCR na detecção de E. coli O157:H7 (Tab. 4). Estes resultados sugerem que a presença de outros microrganismos em alta quantidade no leite dificulta o desenvolvimento e, conseqüentemente, a identificação de $E$. coli O157:H7, provavelmente por competição por nutrientes.
Hu et al. (1999), ao analisarem amostras de fezes de bovinos, concluíram que, apesar de a presença da microbiota natural da amostra continuar presente no meio de enriquecimento, a PCR multiplex não apresentou qualquer reação cruzada com esses microrganismos e que o método de PCR multiplex foi tão eficiente quanto o método tradicional de cultivo. Esses resultados são comparáveis aos resultados verificados neste experimento para o leite estéril e para o leite cru de baixa contaminação microbiana. 
Tabela 4. Comparação dos métodos convencional e PCR na detecção de E. coli O157:H7 inoculada até a extinção em leite cru com alta contaminação microbiana

\begin{tabular}{|c|c|c|c|c|c|c|c|}
\hline \multirow{2}{*}{$\begin{array}{l}\text { Qualidade microbiológica do leite } \\
\text { cru inoculado }\end{array}$} & \multirow{2}{*}{$\begin{array}{c}\text { Inóculo de } E \text {. coli } \\
\text { O157:H7 } \\
\text { (UFC) }\end{array}$} & \multicolumn{3}{|c|}{ Convencional } & \multicolumn{3}{|c|}{ PCR } \\
\hline & & $\mathrm{A}^{*}$ & $\mathrm{~B}^{*}$ & $\mathrm{C}^{*}$ & $\mathrm{~A}^{*}$ & $\mathrm{~B}^{*}$ & $\mathrm{C}^{*}$ \\
\hline \multirow[t]{2}{*}{ Teste 1} & $\sim 20.000$ & + & + & - & + & + & + \\
\hline & $\sim 2.000$ & + & + & + & - & - & - \\
\hline CBT: $3,19 \times 10^{6} \mathrm{UFC} / \mathrm{ml}$ & 195 & - & + & + & - & - & - \\
\hline \multirow[t]{4}{*}{ Coliformes: $2,94 \times 10^{5} \mathrm{UFC} / \mathrm{ml}$} & 24 & + & - & - & - & - & - \\
\hline & 3 & - & - & - & - & - & - \\
\hline & 1 & - & - & - & - & - & - \\
\hline & 0 & - & - & - & - & - & - \\
\hline \multirow[t]{2}{*}{ Teste 2} & $\sim 28.000$ & + & + & + & + & + & + \\
\hline & $\sim 2.800$ & + & + & + & + & + & + \\
\hline CBT: $2,10 \times 10^{6} \mathrm{UFC} / \mathrm{ml}$ & 276 & + & + & + & + & + & + \\
\hline \multirow[t]{4}{*}{ Coliformes: $1,61 \times 10^{5} \mathrm{UFC} / \mathrm{ml}$} & 27 & - & + & - & - & - & + \\
\hline & 4 & - & + & - & - & - & - \\
\hline & 2 & - & - & - & - & - & - \\
\hline & 3 & - & - & - & - & - & - \\
\hline \multirow[t]{2}{*}{ Teste 3} & $\sim 30.000$ & + & + & + & + & + & + \\
\hline & $\sim 3.000$ & + & + & + & + & + & + \\
\hline CBT: $1,02 \times 10^{6} \mathrm{UFC} / \mathrm{ml}$ & 284 & + & + & + & - & - & - \\
\hline \multirow[t]{4}{*}{ Coliformes: $1,63 \times 10^{5} \mathrm{UFC} / \mathrm{ml}$} & 36 & - & - & - & - & - & - \\
\hline & 6 & - & - & - & - & - & - \\
\hline & 1 & - & - & - & - & - & - \\
\hline & 0 & - & - & - & - & - & - \\
\hline
\end{tabular}

CBT: contagem bacteriana total.

* A, B e C: repetição.

+: positivo após incubação a $35^{\circ} \mathrm{C} / 24 \mathrm{~h}$ em meio de enriquecimento (Caldo EC).

-: negativo após incubação a $35^{\circ} \mathrm{C} / 24 \mathrm{~h}$ em meio de enriquecimento (Caldo EC).

Li e Mustapha (2004) testaram a aplicabilidade de uma PCR multiplex em alimentos artificialmente contaminados com E. coli O157:H7, Salmonella Typhimurium e Shigella flexneri e concluíram que o método pode ser utilizado para detecção desses patógenos em diferentes alimentos. Porém, esses autores verificaram que em alimentos com alta contagem microbiana indígena, como em brotos de alfafa, a sensibilidade do teste ficou muito reduzida.

No método convencional, o teste de soroaglutinação para confirmação do isolado bacteriano como apresentador do antígeno flagelar $\mathrm{H} 7$ é um teste extremamente laborioso e demorado, com obtenção dos resultados cerca de 96 horas após o isolamento de colônia típica. Também, Escherichia hermannii, que é sorbitol negativa e aglutina em teste com anticorpo $\mathrm{O} 157$ de $E$. coli, pode ser isolada de fezes e alimentos como leite cru causando erros de diagnóstico (Borczyk et al., 1987). Assim, neste trabalho realizou-se o método de PCR multiplex "A" (específica para genes dos antígenos 0157 e H7) diretamente da colônia bacteriana típica. O DNA bacteriano foi extraído diretamente da colônia por lise térmica (Hu et al., 1999) e a reação de PCR foi feita sob as mesmas condições previamente padronizadas obtendo-se o resultado seis horas após seleção da colônia típica, com total sensibilidade e especificidade. Portanto, quando não se tem conhecimento da CBT do leite cru em análise, deve-se utilizar os dois métodos em conjunto (convencional em placas para isolamento e PCR multiplex para identificação de E. coli O157:H7), que simplificam e otimizam o trabalho.

Até o presente, nenhum trabalho realizado no Brasil detectou E. coli O157:H7 em alimentos (Silveira et al., 1999). No entanto, esse patógeno já foi detectado em rebanhos nacionais (Cerqueira et al. 1999; Gonzalez et al., 2001). Sabendo-se da baixa qualidade da maioria do leite cru produzido no Brasil (Mesquita et al., 2006) e, com base nos resultados obtidos na 
presente pesquisa, pode-se questionar se a ausência desse patógeno em leite e derivados analisados no país reflete realmente a ausência ou a dificuldade de seu isolamento quando presente em baixo número em alimentos com alta carga microbiana.

A microbiota considerada normal do leite pode mascarar espécies patogênicas, as quais normalmente estão presentes em baixo número nos alimentos. Em trabalho realizado para determinar a sobrevivência de E. coli O157:H7 em soro de queijo Cheddar fabricado com leite pasteurizado e não-pasteurizado, Marek et al. (2004) verificaram que o patógeno sobreviveu no soro pasteurizado, em diferentes temperaturas de estocagem, por mais tempo $(\mathrm{P}<0,01)$ do que em não pasteurizado, sugerindo efeito inibitório das bactérias ácido-láticas presentes no soro não pasteurizado em E. coli O157:H7. Esse efeito da microbiota contaminante pode se tornar crítico quando E. coli $\mathrm{O} 157: \mathrm{H} 7$ estiver presente em baixo número nos alimentos.

\section{CONCLUSÕES}

O protocolo de PCR para detecção de E. coli O157:H7 produtoras de Shiga-like toxinas com a padronização de duas PCR multiplex "A" e "B" apresenta total especificidade para detecção de $E$. coli O157:H7 (reação "A") e detecta os genes slt $_{1}$ e slt $_{2}$ (reação "B"),que codificam as toxinas (Shiga-like-toxin 1 e 2), fornecendo informação adicional importante das estirpes identificadas. A capacidade do método de PCR para detecção de E. coli $\mathrm{O} 157: \mathrm{H} 7$ varia segundo a contaminação bacteriana inicial do leite cru e é maior no caso de inoculação desse patógeno em leite estéril e leite cru com baixa contaminação microbiana e menor em leite cru muito contaminado. O método de PCR multiplex "A" utilizado em substituição à soroaglutinação do antígeno flagelar $\mathrm{H} 7$ e somático $\mathrm{O} 157$ permite identificação rápida e acurada de colônias típicas em meio seletivo. Para detecção de Escherichia coli O157:H7 em leite cru, recomenda-se a utilização do método convencional em placas e do método PCR, e, para leite de excelente qualidade microbiológica (baixa CBT), sugere-se a aplicação da técnica de PCR após a etapa de enriquecimento seletivo; para leite com alta CBT, propõe-se a aplicação da PCR após o isolamento de colônias típicas em meio sólido EC-MUG.

\section{AGRADECIMENTOS}

A Fundação de Apoio a Pesquisa do Estado de Minas Gerais - FAPEMIG pelo apoio financeiro (Projeto EDT 2411/05). A Embrapa Gado de Leite (Projeto Prodetab 047-02/99).

\section{REFERÊNCIAS BIBLIOGRÁFICAS}

ARMSTRONG, G.L.; HOLLINGSWORTH, J.; MORRIS, G.J. JR. Emerging foodborne pathogens: Escherichia coli $\mathrm{O} 157: \mathrm{H} 7$ as a model of entry of a new pathogen into the food supply of the developed world. Epidemiol. Rev., v.18, p.29-51, 1996.

BORCZYK, A.A.; KARMALI, M.A.; LIOR, H. et al. Bovine reservoir for verotoxin-producing Escherichia coli O157:H7. Lancet, v.30, p.98, 1987.

BOTTERO, M.T.; DALMASSO, A.; SOGLIA, D. et al. Development of a multiplex PCR assay for the identification of pathogenic genes of Escherichia coli in milk and milk products. Mol. Cell. Probes, v.18, p.283-288, 2004.

CERQUEIRA, A.M.; GUTH, B.E.; JOAQUIM, R.M. et al. High occurrence of Shiga toxinproducing Escherichia coli (STEC) in healthy cattle in Rio de Janeiro State, Brazil. Vet. Microbiol., v.70, p.111-121, 1999.

DOYLE, M.P.; ZHAO, T.; MENG, J. et al. Escherichia coli O157:H7. Foodborne pathogenic bacteria. In: Food Microbiology Fundamentals and Frontiers. Washington, D.C.: Academic, 1997. p.171-191.

GONZALEZ, A.G.M.; COUTINHO, C.A.S.; CERQUEIRA, A.M.F. et al. Virulence markers of shiga toxin-producing Escherichia coli (STEC) O157:H7 and non-O157 isolated from healthy cattle in Rio de Janeiro State, Brazil. In: ANAIS DO CONGRESSO BRASILEIRO DE MICROBIOLOGIA, 21., 2001, Foz do Iguaçu. Anais... Foz do Iguaçu: SBM, 2001. p.104. (Resumo).

FOODBORNE diseases, emerging. World Health Organization, Janeiro de 2002. Disponível em: <www.who.int/mediacentre/factsheets/fs124/en> Acessado em: 30 out. 2004. 
GRIFFIN, P.M.; TAUXE, R.V. The epidemiology of infections caused by Escherichia coli O157:H7, other enterohemorrhagic $E$. coli and the associated hemolytic uremic syndrome. Epidemiol. Rev., v.13, p.60-98, 1991.

HU, Y.; ZHANG, Q.; MEITZLER, J.C. Rapid and sensitive detection of Escherichia coli O157:H7 in bovine faeces by a multiplex PCR. $J$. Appl. Microbiol., v.87, p.867-876, 1999.

JERSEK, B.; TCHERNEVA, E.; RIJPENS, N. et al. Repetitive element sequence-based PCR for species and strain discrimination in the genus Listeria. Lett. Appl. Microbiol., v.23, p.55-60, 1996.

KUNTZ, T.B.;KUNTZ, S.T. Enterohemorrhagic E. coli infection. Primary Care Update Ob/Gyns, v.6, p.192-196, 1999.

LI Y.; MUSTAPHA, A. Simultaneous detection of Escherichia coli O157:H7, Salmonella and Shigella in apple cider and produce by a multiplex PCR. J. Food Protec., v.67, p.27-33, 2004.

MACÊDO, N.R.; MENEZES, C.P.L.; LAGE, A.P. et al. Detecção de cepas patogênicas pela PCR multiplex e avaliação da sensibilidade a antimicrobianos de Escherichia coli isoladas de leitões diarréicos. Arq. Bras. Med. Vet. Zootec., v.59, p.1117-1123, 2007.

MAREK, P.; NAIR, M.K.M.; HOAGLAND, T. et al. Survival and growth characteristics of Escherichia coli $0157: \mathrm{H7}$ in pasteurized and unpasteurized Cheddar cheese whey. Int. J. Food Microbiol., v.94, p.1-7, 2004.

MECHIE, S.C.; CHAPMAN, P.A.; SIDDONS, C.A. A fifteen month study of Escherichia coli O157:H7 in a dairy herd. Epidemiol. Infect., v.188, p.17-25, 1997.

MESQUITA, A.J.; DURR, J.W.; COELHO, K.O. Perspectivas e avanços da qualidade do leite no Brasil. Goiânia: Talento, 2006. 352p.

NUNES, E.L.C.; SANTOS, K.R.N.; MONDINO, P.J.J. et al. Detection of ileS-2 gene encoding mupirocin resistance in methicillinresistant Staphylococcus aureus by multiplex PCR. Diag. Microbiol. Infect. Dis., v.34, p.7781, 1999.

SILVEIRA, N.F.A.; SILVA, N.; CONTRERAS, C. et al. Occurrence of Escherichia coli O157:H7 in hamburgers produced in Brazil. J. Food Protec., v.62,p.1333-1335, 1999. 